\title{
Electronic and Micrographic Publishing, Cost Effectiveness, and Accessibility
}

\author{
IAN MONTAGNES*
}

\begin{abstract}
The author considers the major advantages and disadvantages of electronic publishing for the academic community. He considers economic issues in terms of both obvious and hidden costs for both publishers and users, as well as a variety of non-economic questions such as access for authors and readers, motivation of scholars, appropriateness of subject areas, storage, the implications of centralization and standardization, copyright, and implications for libraries. He also examines the history and future potential of microforms. He concludes that sciences will move first to electronic publishing, and that the spread will be gradual. He cautions against moving too quickly in this area.
\end{abstract}

\section{RÉSUMÉ}

L'auteur discute des principaux avantages et désavantages reliés à l'édition et aux innovations technologiques dans le monde académique. Il traite des aspects économiques, tels que les coûts directs et indirects pour les éditeurs et les utilisateurs de la littérature. Il examine également toute une série de questions relatives à l'accessibilité à l'information, la motivation des chercheurs, la sélection de domaines d'études, la conservation de l'information et la standardisation; les implications pour les droits d'auteurs et pour les bibliothèques sont aussi abordées. Après une brève présentation historique et futuriste de la microphotographie, l'auteur en conclut que les domaines scientifiques se prévaudront d'abord des innovations technologiques pour ensuite se propager aux autres domaines d'études. Finalement, il incite les personnes concernées à s'engager avec prudence dans les nouvelles technologies reliẻes à l'édition savante.

\footnotetext{
* Assistant Director and Editor-in-Chief, University of Toronto Press
} 
To exploit technological developments in order to make scholarly communication more cost-effective and more broadly accessible is a goal that Canada's scholarly publishers have pursued for several years. Some houses have been active in microform publication, with varying results, for more than a decade. Nearly all have been employing the computer or micro-processor in a variety of applications: preparation of manuscripts by authors or editors; capture of author's keystrokes for photocomposition; computer-assisted photocomposition, sometimes employing optical character recognition; computerized promotional and subscription mailing lists; and computer-assisted business functions including sales analyses, stock control, and invoicing. The employment of the 'new technology', when successful, has been gradual. Abrupt changes are apt to create problems. This has been evident in other areas of endeavour as well: who can forget the fallout when Eaton's too rapidly computerized its accounting system?

Before any radical reallocation of financial support to 'innovative techniques' is approved, I would urge the careful consideration of a number of questions.

\section{ELECTRONIC PUBLICATION}

There is a growing body of literature about electronic publishing and document delivery. Much emanates from Europe, where the importance of international co-operation has engendered several years of study and test projects, but there have also been important studies in the United States (Anthony, 1980; King, McDonald \& Roderer, 1981; Oakeshott \& Bradley, 1982; Singleton, 1981). In this literature there are several points of general agreement.

Although electronic communication of the results of scholarly research is technologically feasible, electronic communication is particularly suitable for only some kinds of information. One author distinguishes between 'access material' (for which it is suitable) and 'narrative material' (for which it is not) (Cox, 1982). Others list as suitable 'the ephemeral, succinct, factual work needing constant revision where access is required only for reference; information in definable subject areas or involving many scattered references where speed of access is vital'. They list as unsuitable: 'creative writing, discursive, explanatory, interpretative material; argument and discussion; browsing material; high quality illustrations' (Oakeshott \& Bradley, 1982, p. 21). Videotex systems such as Telidon or the British Prestel, which are based on hierarchical organization of small 'pages' of data, are particularly restricted by their nature to distribution of short items of reference in need of frequent revision. Clearly, the application of the new technology must be highly selective.

\section{Advantages and Disadvantages}

Electronic communication has some distinct advantages over print-on-paper. These include speed, flexibility, direct author-editor-reader interaction, and a saving in resources. An integrated system, moreover, could help reduce duplicate or overlapping publication of the same research, reworked, in more than one journal. 
Electronic communication also has severe disadvantages. Most important is its dependence on access to a terminal. This limits use by authors and readers. Until terminals are ubiquitous in home and office, access to any electronic system of communication will be restricted to central institutions such as university libraries: the scholar without his own terminal will be tied to the library much as his forebear was in medieval days when books were chained to the shelves. This situation will unquestionably improve with time, but can never disappear. Another limitation, which is inherent in the medium, is the difficulty of browsing. The serendipitous discoveries of the browser have produced some of the most illuminating of scholarly insights (Harold Innis being a prime example of the literary omnivore), but there are more practical considerations: a recent study found that browsing in journal issues was still, among social scientists as well as other scientists, the most common method of finding useful articles despite the spread of indexing and abstracting services (King, McDonald \& Roderer, 1981). A more resolvable limitation on electronic communications is the current cost and difficulty of transmitting graphic materials.

The academic community tends to be conservative. It is still reluctant to use microform, even after more than fifty years of exposure to it; the same resistance will be met in response to electronic methods of communication. This cannot be ignored, although it will likely decline. Promise is to be found in a recent survey of deans and chairmen in the United States, which found acceptance, albeit by a slim majority, of electronic publication as a criterion for promotion or tenure, provided publication in the new medium was national in scope, referred, and in the author's specialty. Even so, many of the respondents expressed reservations (Seiler \& Raben, 1981).

\section{Electronic Journal Experiment}

The human engineering of any system of electronic communication is allimportant - the problems that arise at the man/machine interface. This was the Achilles heel of a pioneer experiment in the electronic journal sponsored by the U.S. National Science Foundation and administered by John Senders, professor of industrial engineering at the University of Toronto. He has summed up the experience: 'I have seen the future, and it doesn't work' (Senders, 1981). Less dramatically, he concluded that the electronic journal is inevitable, but that:

A system must do what people want it to do or it will be a failure.

It had been our intention to speed up the exchange of scientific information. The system did not do what was wanted and it failed. It was intended to permit the creation of interactive groups working on a common problem. This could be done, but the extensions of these groups into a genuine journal failed. The failure can be traced directly to the human engineering of the system, or rather, its absence. It was too hard to do things, so they were not done. (p. 9)

There has been a considerable amount written about this experiment, probably the most ambitious of its kind. In another account of it, two participants (Turoff \& Hiltz, 1982) laid the blame largely on motivation: 
The original plan for this electronic journal on mental workload called for it to be advertised, refereed, edited, copyrighted, and mass distributed - just as are traditional journals. Some demonstration of the feasibility of the concept did occur, but for the most part the plans did not come to fruition...

It is not difficult to do this technologically. The results should show a much shorter cycle from completion of research to dissemination of findings. Cost should also be lower, since each reader prints only those articles of interest. The difficult problem is a motivational one. How do you motivate people to take the risk of expending effort to write and review for an electronic journal which has no established prestige-granting rating in the scientific community? For, besides serving as official archives of research findings, journals also serve as bestowers of prestige. (p. 197)

Participants in this experiment were asked what factors had limited their use of the electronic journal. The responses suggest that failings in both human engineering and human motivation were roughly equal in their impact. Seventeen participants answered a multiple-choice questionnaire. Of these, 11 said that other professional priorities had taken higher priority. Fifteen responses cited technical factors: inconvenient access to a terminal, too complicated a system, trouble with the telephone or Telenet, cost, limited night or evening hours, bad experiences, or sheer dislike of using a computer system. One remarked candidly: 'The conference comments or messages I have received do not seem worth reading.'

The Electronic Information Exchange System (EIES) within which this electronic journal operated is being used more successfully for other forms of electronic scholarly communication - a newsletter, an unrefereed journal which includes a poetry corner, and a 'notebook' which handles inquiries, responses, and brief papers. Nevertheless, the authors of this account concluded that:

We are still at least a decade away from substantially supplementing print-based journals with electronic ones. (p. 198)

(For more information, see Featheringham, 1981.)

The spread of electronic publishing will be gradual. And for a long time, readers will want access to both conventional and non-conventional methods of communication. Parallel publication is uneconomic, but for some time it will be unavoidable unless all current subscribers to journals, or potential readers of books, without access to the electronic medium are to be abandoned.

\section{ECONOMICS OF ELECTRONIC PUBLICATION}

The costs of this new means of scholarly communication are hard to pin down. One scientist found it 'particularly difficult to develop current and projected cost estimates for the enhanced use of computerized scientific information (Bloom, Note 1). The same conclusion underlies the report of an exhibition and workshop at which equipment manufacturers and system designers presented proposals for an electronic document delivery system at the invitation of the Commission of the European Communities (Page, 1980), and some of the com- 
plexities are outlined by Singleton (1981). Reports generally agree that initial investment will be high and (for those operating in the market) returns low. The operating costs of input, storage, and connect time are all substantial. Two estimates give some idea of the operating costs that may be involved, and the imprecision of predictions. In 1980, the operating costs of a dedicated electronic mail and teleconferencing service for 1000 users in the United States were estimated at $\$ 400$ to $\$ 600$ per year per user. Price, Turoff, and Hiltz (1980) remarked that these figures were 'very close to the current costs of some specialized journals and paper-based information services' and that 'when the per-user cost declines to perhaps half this amount (likely within the next five years), a very competitive marketplace will evolve, (p. 37). Even halved, however, the costs are far above the subscription price of any Canadian journal sponsored by SSHRCC, or even of any logical combination of such journals. Another estimate placed the tentative cost of on-line text retrieval at $\$ 1-5$ for printing a ten-page article on a terminal (Myatt, quoted in Lewis, 1980). Proponents of electronic publishing, such as Seiler \& Raben, are quick to recognize costs as well as benefits:

In the short run, electronic publication will be enormously expensive. Each library will need a computer. Ultimately each faculty office will require a terminal with substantial memory capacity and phone (or hardware equivalent) to connect it to the main computer. Students will need access to terminals. Many faculty and students will want to access the library from home. If one adds the costs of software and programming, maintenance, auxiliary equipment, and updating as new generations of hardware are developed, then establishing electronic publication will indeed be a costly enterprise. Against this expense must be balanced, however, the savings to be achieved by eliminating the expense of replacing lost or stolen books and journals, postage, accessioning by libraries, and repairs to damaged printed materials. (p. 82)

Costs are dropping significantly, and sometime in the future a cross-over point will be reached at which electronic journals will be more economical than printed ones. Senders et al (Note 2) calculated, some years ago, that that point would be reached in 1996; their estimate could not, of course, have taken into account subsequent rapid technological advances, but on the other hand it did not recognize many of the hidden costs of publishing. Turoff and Hiltz (1982) argue that the current technology is already 'quite cost competitive with technical journals with readership in the under 10,000 category' (p. 201), but their analysis is far from rigorous. A recent prediction is that demand for full-text articles by telecommunication will be limited through the short term unless some major breakthroughs occur in computer output costs, transmission costs, and technology for digital input and output of special graphic material (King \& al, 1981).

\section{A System Approach to Costs}

The hidden costs of publishing are critical to its success, regardless of medium or auspices. They are what make the publisher more than a transmission belt linking 
author and consumer. The publisher is also gatekeeper, enhancer, and distributor. He selects what is to be published, in the case of a scholarly publisher using expert outside referees: his imprint, whether of a journal or of a house or of a sponsoring society, is a guarantee of quality for potential readers. He edits so as to bring clarity and consistency to text, to ease the work of potential readers. Through diverse promotional channels (including key bibliographic listings) he ensures that the publication, whether book or report or journal article, is made known to potential readers. To do less is to threaten the quality and coherence of what is published, to reduce the formality and ordering of scholarly communication, and to restrict its potential readership. (See Montagnes, 1981; Strawhorn, 1981.)

Any economic analysis of electronic publishing must also take into account the transfer of costs from individuals to institutions. At present, journals have substantial numbers of individual subscribers as well as libraries and other institutional subscribers. An electronic journal would depend principally on institutions that had the necessary equipment and network connections. Authors for the most part would enter material through their universities or other institutions. Access by both author and reader would thus be shifted to the local institution. Whether the institution has to buy equipment for the purpose, or makes use of available computer facilities, is of only partial significance; as universities and other centres feel the financial pinch, they will place increasing pressure on their computer services to recover true costs of operation. Libraries will also have to administer charges to on-line users. 'Computerized operations and services, while sometimes cost effective individually, represent new costs in the aggregate, in part because they often complement rather than replace existing services and in part because communications open a new cost category and imply a new pricing structure for information itself' (Haas, 1982, p. 861).

An analysis of the costs of communicating by journals in technical and scientific fields (including the social sciences) in the United States indicates that of the total cost, from research through to final use, $12 \%$ is incurred in writing, submission, revising, and proofreading by the author; $14 \%$ in publishing; $10 \%$ in acquisition and service by libraries and secondary organizations; and $64 \%$ by the user of the information. The last figure includes individual acquisition and storage of journals, searching, photocopying, and reading. Reading alone represents over one-half of the total cost of journal communication (King \& al, 1981). Such a systems analysis suggests that a radical change in the means of publication would have only a relatively small effect on total costs of communication, and that anything which might jeopardize the access of the ultimate user to the material he needs, or the efficiency of his reading of it, would have a major impact.

The cost-effectiveness of innovative projects, in short, will be complex to determine but should be studied with care, including in it all stages in the process of publication and communication. 


\section{NON-ECONOMIC QUESTIONS}

A number of non-economic questions must also be examined in connection with any venture into electronic publication. Stated very briefly, these include the following areas of concern.

Who will have access as authors to the electronic publication? What steps can be taken to ensure that all authors who may now submit articles to existing journals will still be able to do so if an electronic medium is used? Obviously, articles can be submitted to an electronic journal by mail, and edited and entered into the electronic network at a central office. Current practices and technology, and costs, will then be incurred up to that point. The alternative, however - a fully electronic journal - would limit authorship to scholars with access to terminals.

Who will have access as readers to the electronic publication? Will any provision be made for scholars without access through terminals? Canadian scholarly journals have broad international distribution in print. Any successful electronic publication must have equally broad dissemination if Canadian scholars are to be part of the international academic community. Canadian innovations in this area must therefore be compatible with similar developments elsewhere, most notably the United States, Britain, France, and other major European countries where experiments in this area are under way. Regulatory impediments must also be considered: in the electronic journal experiment already referred to, British scholars were barred from participating by a ruling of the British Post Office.

What can be done to motivate scholars to make use of electronic publications? The attention that must be paid to human engineering has already'been mentioned. In addition, authors must be assured that they can reach their colleagues - outside as well as inside Canada - effectively; that they will achieve prestige and recognition equivalent to that granted by traditional publication; and that electronic publication will establish priority of publication as efficiently as print. Academic recognition will require of the electronic medium an editorial apparatus, with refereeing, equivalent to those now in place for traditional methods of scholarly communication.

What subject areas are most suitable to electronic publication? Which should be chosen for experimentation? This has already been touched upon. The bulk of work in the humanities and much in the social sciences is explanatory or interpretative, argument or discussion, intended for browsing or reflection, or in need of high-quality illustration. Only a portion is essentially for reference or in need of frequent revision. A journal of computational linguistics would be an obvious candidate for electronic publication; the Canadian Historical Review or Seminar is not.

Who will store the digitized data that constitutes the inventory of electronic publication? This is a serious and not inexpensive responsibility. It is essential if works are to remain electronically 'in print' and available to scholars of the future, remembering that, particularly in the humanities, the life of an article or book may extend over decades rather than years. There will be no source of 
electronically published material apart from this digitized storage - unless, alternatively, provision is made for transferring the material to another medium, such as computer-generated microfiche, to be held available in some new central facility, or libraries go to the expense of ordering, binding, and preserving printouts, thus incurring the expense they were intended to be saved.

What are the implications of standardization and centralization? A free flow of information through electronic networks, both intra- and internationally, will require standardization of systems. (The failure to achieve any international standardization in another new electronic technology, video, means that, after more than a quarter of a century, the worldwide standard visual medium is still $16 \mathrm{~mm}$ film (Cox, 1982).) But standardization will involve governments; and some scholars fear that state intervention could lead to restrictions on freedom of publication (Meadows, 1980). High capital costs, economies of scale in editorial functions, responsibilities for storage, all tend towards centralization. Potentially this also could limit access to electronically published material, though the basis would be economic, technical, or commercial rather than political; a privileged class of user could be created.

What protection will be afforded authors? The Canada Copyright Act now in force was passed in 1924. It is currently under revision. New legislation should ensure that authors published through electronic networks be rewarded for use of their intellectual property. Provision will have to be made in any electronic system for recording the use of material and accounting for royalties or fees.

What are the implications for library use and budgets? Among concerns expressed by librarians, in addition to questions of access, are the following: the potential for concentration of traffic in a few institutions; the possible need for dedicated hardware - or, if there is no standardization, the need for a 'machine shop,' a multiplicity of hardware; foreseeable difficulties in recording and recovering costs from on-line users; difficulties in using equipment and software that may be designed for technologists rather than laymen; problems of bibliographic control, especially for large packages of data such as videodiscs (Leamy, 1982; Lehmann, 1980).

What happens when the system is down? Anyone who has used a computer knows the answer.

The need to examine questions of this kind has launched the International Electronic Publishing Research Centre in England. It has defined the following areas for examination: technology monitoring; techno-economic forecasting; socio-technical environment research; standards; producer/user interface studies; market studies; technology studies; education and training projects; demonstration projects; development of publishers' performance specifications for electronic publishing; software commissioning and evaluation. The list suggests both the range of the problems to be considered before any major commitment is made to electronic publishing and an ally in the search of answers. 


\section{MICROFORM PUBLICATION}

Microform shares some characteristics with electronic publishing. Both are read from screens, and are consequently more difficult to use for protracted periods than print on paper. Both are more suited for reference than for reflective material. Neither is suitable for browsing, or for easy comparison of pages. Both, however, can provide large packages of data economically. Microfiche has proved most useful in making available large stores of documents (Parliamentary papers or diaries, for example) in unedited, unannotated, original form; and for distributing equally large assemblages of research reports, such as those emanating from NASA or the grab-bag of educational materials labelled ERIC. Attempts to publish books simultaneously in traditional form and in microfiche have proved disastrous. So have some major publishing microform projects. Publication of journals by microfiche has been limited and not always successful (see Montagnes, 1975, for a general discussion of the potential and limitations of the medium).

Microforms were long hailed as a means of economical publication and cheap library storage. Now some people are talking about a 'microform failure' with the following as contributory causes: 1) the cost of microforms (see below); 2) the lack of low-priced, easy-to-use plain-paper copiers; 3) the lack of standardization in microform formats; 4) the absence of and difficulty of quality control; 5) the rigidity in use of microforms (Vervliet, 1980).

Unlike electronic publishing, microforms are distributed physically, typically through the mail, and thus conform to the same procedures as books or journals printed on paper. The same appraisal, promotion, distribution, and business processes and costs prevail. Composition costs may be avoided if the microforms are photographed from typescript or original matter; print publishers can achieve the same savings by reproducing from typed pages supplied by the author. The major saving in microform thus is in the running costs (the equivalent of conventional paper, printing, and binding); but the present cost of archival-quality silver halide microfiches is not negligible. Potential revenue from sales of microfiche publications, on the other hand, is less than for print-on-paper because of resistance among librarians and readers to the medium: list prices must be lower and print runs smaller than for print-on-paper, even though overheads remain much the same. Some overhead costs in fact are higher: it would be more expensive, for example, to mail a journal in microfiche ( 32 cents) than by the second class rate available to print.

King et al (1981) conclude: 'The problem is that the savings in reproduction (runoff) costs with microform are not great enough to overcome the large prerun costs. Thus prices cannot be sufficiently reduced to induce libraries or scientists to purchase this form of distribution' (p. 292). And for the future they predict: 'It is anticipated that not many libraries will subscribe to microform journals because the price will not be much less than for paper copies and the advantages do not outweigh the disadvantages' (p. 301). 


\section{CONCLUSION}

It is far from clear whether, or to what extent, electronic or microform publication will contribute to greater cost effectiveness and greater accessibility of materials embodying the results of scholarly research. More study is required to determine these questions.

It is safe to predict, however, that the benefits of the new technology will first be felt in the sciences, where greater importance is placed on speedy dissem. ination of small increments of information and journal prices have risen much higher than in the humanities or social sciences. The first commercial electronic journal is starting in the United States; the publisher, Comtex Scientific, hopes eventually to have 22 such scientific journals on-line throughout North America. The scientific community views the development with mixed feeling. The material will be largely progress reports normally filed periodically with government funding agencies. The refereeing will be by an editorial board which will either accept or reject: there will be no editorial revision. The result, a traditional editor predicted, will be 'an electronic garbage heap.' On the other hand, papers will be published within six to eight weeks; and despite on-line charges of $\$ 90$ an hour, Comtex costs appear attractive to librarians who are now paying subscription prices of several hundred dollars a year for some journals (see Broad, 1982).

In the humanities and social sciences, the forces that have encouraged the Comtex initiative are far less strong. As part of further study of electronic and microform publication, other financial approaches that could reduce the need for subsidies, especially of journals, should be examined. Page charges, common elsewhere in the sciences, could be introduced in a limited manner. Journals with small circulations could be encouraged to print from typed pages supplied by the authors to fixed specifications (and after initial copy editing). Experiments could be made with synoptic publication: only a synopsis would appear in the journal, with the full paper available on demand in hard copy or microfiche (see Manten, 1980). Subscription rates could be increased and still remain within international market levels.

To quote the president of the Council on Library Resources (Haas, 1982):

The scholarly world does have an obligation to see that the institutions and organizations it values are not jeopardized by the competition for funds that is implicit in the introduction of new and costly systems that, despite strong assertions to the contrary, will probably supplement rather than supplant printed books, scholarly journals, and research libraries. (p. 861)

Canadian scholars and publishers must adapt to the technology of computers and microforms - and they have been doing so. But over-response to technological potential can be as disastrous as no response, particularly if it means starving the conventional means of publication on which, the evidence suggests, the academic community will still have principally to depend for some years in the future. 


\section{REFERENCE NOTES}

1. Bloom, F.E. Personal communication from W.J. Haas, June 1982.

2. Senders, J.W., Anderson, C.M.B., \& Hecht, C.D. Scientific Publication Systems: An Analysis of Past, Present and Future Methods of Scientific Communication. Unpublished report submitted to the National Science Foundation, 1975.

\section{REFERENCES}

Anthony, L.J. (Ed.). EURIM 4: A European Conference on Innovation in Primary Publication: Impact on Producers and Users. London: Aslib, 1980.

Broad, W.J. Journals: fearing the electronic future. Science, 1982, 216, 964-8.

Cox, J. New means of communication and book provision. In P. Oakeshott \& C. Bradley (Eds.), The Future of the Book: Part I - The Impact of New Technologies. Paris: Unesco, 1982.

Featheringham, T.R. Paperless publishing and potential institutional change. Scholarly Publishing, 1981, 13, 19-30.

Haas, W. J. Computing in documentation and scholarly research. Science, 1982, 215, 857-861.

King, D.W., McDonald, D.D., \& Roderer, M.K. Scientific Journals in the United States: Their Production, Use, and Economics. Stroudsburg, PA: Hutchinson Ross, 1981.

Leamy, C.C. Library and information services. In P. Oakeshott \& C. Bradley (Eds.), The Future of the Book: PartI - The Impact of New Technologies. Paris: Unesco, 1982.

Lehmann, K.D. The librarian's point of view with regard to electronic publishing. In J.R.U. Page (Ed.), Electronic Document Delivery: Proceedings of an Exhibition and Workshop. Luxembourg, 1980.

Lewis, D.A. Today's challenge - tomorrow's choice. Journal of Information Science, 1980 , 2, 59-74.

Manten, A.A. Synopsis journals. In L.J. Anthony (Ed.), EURIM 4: A European Conference on Innovation in Primary Publication: Impact on Producers and Users. London, Aslib, 1980.

Meadows, A.J. The effect of new technology on learned societies and journal publications. In L.J. Anthony (Ed.), EURIM 4: A European Conference on Innovation in Primary Publication: Impact on Producers and Users. London: Aslib, 1980.

Montagnes, I. Microfiche and the scholarly publisher. Scholarly Publishing, 1975, 7, 63-84.

Montagnes, I. Some notes on the new technology. In Symposium on Scholarly Communication. Ottawa: Aid to Scholarly Publications Programme (CFH/SSFC), 1981.

Oakeshott, P., \& Bradley, C. (Eds.). The Future of the Book: Part I - The Impact of New Technologies. Paris: Unesco, 1982.

Page, J.R.U. (Ed.). Electronic Document Delivery: Proceedings of an Exhibition and Workshop. Luxembourg, 1980.

Price, C.R., Turoff, M., \& Hiltz, S.R. Electronic mail and teleconferencing: "information" or "communication". In L.J. Anthony (Ed.), EURIM 4: A European Conference on Innovation in Primary Publication: Impact on Producers and Users. London: Aslib, 1980.

Seiler, L.H., \& Raben, J. The electronic journal. Culture and Society. September/October 1981,81 .

Senders, J.W. I have seen the future, and it doesn't work: the electronic journal experiment. In E.G. Langlois (Ed.), Scholarly Publishing in an Era of Change, Proceedings of the Second Annual Meeting of the Society for Scholarly Publishing. Washington, SSP, 1981. 
Singleton, A. The electronic journal and its relatives. Scholarly Publishing, 1981, 13, 3-18. Strawhorn, J.M. Word processing and publishing. Scholarly Publishing, 1981, 12, 109-21.

Turoff, M., \& Hiltz, S.R. The electronic journal: a progress report. Journal of the American Society for Information Science, 1982, 33, 195-202.

Vervliet, H.D.L. Technological innovation in libraries and information services: their effects particularly on the structure and function of libraries. In L.J. Anthony (Ed.), EURIM 4: A European Conference on Innovation in Primary Publication: Impact on Producers and Users. London: Aslib, 1980. 